\title{
The Effects of Usability and Accessibility for E-Government Services on the End-User Satisfaction
}

\author{
https://doi.org/10.3991/ijim.v14i13.14659 \\ Mohammad H. Alshira'H \\ Al al-Bayt University, Mafraq, Jordan \\ alshirah@aabu.edu.jo
}

\begin{abstract}
The research aimed to discover the effects of website usability and accessibility on the satisfaction of the end-user. To achieve the aims of the research, the questionnaire was used. The outcomes of the research found that all the participants had a positive agreeing that website usability for e-government services. Also, the participants were agreeing that website accessibility for egovernment services designs in Jordan have good agreement, responses were positive towards that. Besides, there is a positive effect of website usability on the satisfaction of the end-user on e-government website designs in Jordan. In addition, the result showed that there is a positive impact of website accessibility on the satisfaction of the end-user on e-government website designs in Jordan. The research recommended that the user interfaces and website accessibility in the Jordanian e-government website designs must further be developed to attract more users and maintaining user satisfaction. And, Jordan e-government systems must be maintaining a high degree of integration and flexibility to attract more users.
\end{abstract}

Keywords-Website Usability, Website Accessibility, Human Computer Interaction, End-User Satisfaction.

\section{$1 \quad$ Introduction and Background}

The software designs must be accessible and easy to use; this saying has become an integral principle of the integrated system for the success of any site or software, especially after the sites have become more sophisticated in their content and services to the public, the site that applies the concept of "user-based design". User-Central Design is concerned that the site primarily accomplishes the goals and desires of the users, and makes sure that both the services and functions of the site can be used easily and quickly. A large and growing body of recent research has investigated the usability concept [21], [22], [23]. The usability concept refers to the evaluation operation of enduser response and interaction conduct to the implemented system if it authorizes them to tell about the personal effect of resources such as satisfaction, interest, worth, helpfulness, advantages, frustration, and self-efficacy [11]. 
Usability is the most popular notion in Human Interaction research. It generally contains the evaluation of ease and effective phase when end-users applied new outputs to implement ant missions. Thus, usability can be beheld as the excellence of electronic systems of ease of use, learning, and user contentment aspects. Just like the IT system usability point to the "effectiveness, efficiency and satisfaction" with a particular goal in the specific term of use. The usability displays the ease of understanding the system, ease of port realization, the speed of locating the item, the understood phase of port navigating, and the ability of end-users to manage their effectiveness inside the port [6]. As well As, the comprehensive of usability and accessibility are crucial matter in their design, that driving is to the requirement which developers want to tool up the attributes of usability and accessibility while adopting software designs.

The assessment of the usability and accessibility of the adoption for software designs. Moreover, usable systems have been assured to produce huge savings and raised benefits. On this basis, new software system developers adopt usability features in mind when developing and designing new websites and software. Moreover, the human-computer interface presented has usability somewhat suggesting recommendations and methods for building usable interactive systems. In addition, the certification of their usability in the program has been recognized as comprehensive access to services through a phased operation. Usability was examined as a non-possible request in relation to the exclusive user interface; it was determined until the end of the expansion process and was performed using access that separated the user interface function from the functionality of the platform [18]. Add to that, usability can be described as an integration of quality components where this component characterized the ease level of the operative user interface of products or services. Moreover, usability refers to the transfer to create services easier to use [4].

Further, accessibility concept is related to the usability, it can be sort as design the applications that have the capability to ingest the disabled, likewise, the accessibility considered as a lawful matter that the e-government gave to rely on while using new technology to help people with disabilities [1].

Since that usability is not a science restricted to the web and websites only, usability is included in everything that a person interacts with, usability appears in another field that shares with the web domain in the target group and the foundations and philosophies based on it; it is a field that is the industry of software applications, each program has an interface Special use and may differ from the operating system's operating interface [10]. Moreover, usability is a condition of familiarity over time. So, usability is a feature in the product resulting from the user's familiarity with the product over time. The usable product is the product that you can use using previous experiences that you have received and "learned" and stored in your depths, without the need to learn something new, and then the use of This product is difficult whenever you find yourself needing to learn more before you can use it [15].

As well as, to measure the usability of software products, it must first define a specific former software product as a measure of the usability of the new product. Windows and Office software are considered as the standard base or standard platform against which the use of other programs operating in the Windows environment is measured. Likewise in the Linux world, it must adopt a specific Linux distribution as a standard 
or platform that it must as a user of the Linux system learn first, before testing any other software product that works In that environment to try to assess its usability [17], [14]. Assuming that the operating system is a standard for measurement, the user will notice that the interface of this platform includes a set of icons, colors, and shapes that represent (User Interface components), which can be classified into three main categories [13]:

- The interface of any operating system with icons, words describing them, and windows.

- A set of terms such as words that are placed over icons or contained in application lists.

- Set icons such as save, copy, and align icons.

- Windows group (open / save / save as / choose font / choose color etc.).

In contrast, each software product may have its own list of components (specifically, those components that are not included in the platform component list). And the more the program's interface depends on the (user interface components) of the operating system, the greater its usability. In addition, it has to measure the usability of any new product or software design that must be followed that the greater the dependence of this product or software designed on the (user interface components) of the platform, the more usability. In turn, the more a group of its own user interface components is created, the less usability [3] [8]. Depend on the foregoing, it can be deduce that the balance of usability and operating system icons versus application icons that design, and orderly to make sure the highest levels of usability, software developers should work to attain the maximum benefit from those components provided by the platform (terminology, icons, and interface components), to achieve what is called external consistency. From other hand, government websites aim to measure and improve the level of customer experience in using online services on the site. It also monitors and measures the development of website services within a number of indicators to reach the goal of establishing and designing its websites. The most important indicators that are used to measure customer experience and satisfaction while using websites to benefit from their services [2]:

- Transformation level indicator for using the electronic service

- The percentage of using electronic services

- Customer satisfaction index for electronic services

- Public awareness degree index using electronic services

- Web Quality Index

- Quality index of electronic services

- Smart services integration index

As well as, the main importance of usability and accessibility is to create services and data obtained by the big scale of the popular; these users include people with any kind of inability "visual, hearing, physical, speech, cognitive and neurological impairments". The capability to arrive by everyone at any case of disability is a major aspect', so the design for all has clear benefits and it is a legal commitment. Usability and 
accessibility in the web affect many sides such as its effect on user satisfaction, also its effect on efficiency and effectiveness of website usage. Many previous studies tell that accessibility and usability integrated and interferes with each other. The usability focused on the show the concentration on many attributes like effectiveness, efficiency, and satisfaction however, the accessibility focused on arrival by people with abilities [16]. In Costagliola et al. [7] study aimed to describe how the quality of web applications, accessibility and usability could affect the improvement of web applications. The study represented that the classification of a problem as minor, major depends on the degree of criticality of the problem for the user experience. Moreover, the study showed that the quality of web applications, accessibility and usability could affect the improvement of web applications on distinguishing possible confusion controlled by vocabulary changes between designers and users and to better understand user's perspective. Moreover, Huber and Vitouch's study [12] aimed to examine the relations between webaccessibility and web-usability. To analyses, this relation the researcher intended an in real time examination environment. To improved complete test portals, all different phase of accessibility. The conclusions lead to show a significant difference in the usability evaluations of the portals. Moreover, the result showed that there is an influence partly significant on disability and age factors. In Brajnik study [4] claims that procedures for observing, measuring and make sure suitable phases of "accessibility and usability" have to be approved by web improvement and repairs teams. The study result showed that examination web improvement and repairs actions that highlight the details why accessibility and usability are so out of sorts accomplished. Further, the study result showed how automatic instruments could appropriate in those procedures.

And the researcher sees that, in order to estimate the usability of any designed program interface, a specific method must be identified for calculating the positive and negative points in it:

- Positive points: represent the elements (icons - words - windows) that are quoted from the operating system on which the program is running; which are (the number of icons in the operating system and the number of symbols used in the interface of the program designed, number of component calls to platform's user interface in the software product).

- Negative points: They represent the creations of new elements (icons - words - windows) in the program's interface that are different from the interface of the operating system; which are (the number of icons for the program, the number of terms for the program, and the number of components for the program).

The relation between usability and accessibility in software design is being debated; at conferences, websites, and in meetings and debate between those who work in this domain. In spite of a growing benefit in the matter, much of the debate has known from a distinct lack of visibility and depth. This leaves grasp of the relation unclear, and practitioners and advocates of all approaches unsure about how this should influence their work. Therefore, because of the importance of ease of use and access in the design of websites and programs, the idea of this research paper came to discuss the effects of website usability and accessibility for government website designs on the end-user 
satisfaction about some of e-government websites, which have recently become a major place in Jordanian government systems.

\section{$2 \quad$ Problem Statement and Research Questions}

In the last decade, the use of software designs and websites has been increasing, and the number of users accessing them is steadily arising. Accordingly, it is sustainable that the data be easily reachable by all. The hardness in providing like global arrival can be addressed during the application of the rules of usability and accessibility. Thus, this study aimed to determine the effects of website usability and accessibility for software designs on end-user satisfaction about some of e-government websites. The current research seeks to find answer for the fowling main questions.

1. Are there effects of website usability for government website designs on end-user satisfaction?

2. Are there effects of website accessibility for government website designs on enduser satisfaction?

\subsection{Research motivation and importance}

Although the fact of website usability and accessibility for software designs and the satisfaction of the end-user has become a key interest in all of the developer designs, some software designs projects fail and are failing to meet its expectations. Although usability and accessibility influencing users of software designs, besides software design success and failure, there seem to be a number of constraints when takeover into sight the usability and accessibility aspects of government website designs. According to usability and accessibility influencing users of software designs besides success and failure, there seems to be a number of constraints when taking into consideration the usability and accessibility aspects of. Furthermore, it appears that there are very few studies, which examine the effects of website usability and accessibility for software designs on end-user satisfaction, therefore, this proposal for further research, which investigates the effects of website usability and accessibility for government website designs on end-user satisfaction to fill this literature gap. Furthermore, the current research will be useful and will assist to create guidance on websites. The current research significance stems from represents with the presentation and formalization of road map to help software design decision-makers to make an ideal and friendly website.

\section{Research Aim and Objectives}

The core goal of the current research represented in to discover the effects of website usability and accessibility for software designs on the satisfaction of the end-user. From this main aim, sub-aims have been raised also they are represented in the following: 
1. Explore the effects of website usability the effects of website usability and accessibility for government website designs on the end-user satisfaction

2. Explore the effects of website accessibility the effects of website usability and accessibility for government website designs on the end-user satisfaction

\section{$4 \quad$ Methodology}

The research followed the descriptive-analytical approach, which is considered the best among other approaches when conducting an apparent study as it is in reality.

\subsection{Research tool}

In this paper, the questionnaire was designed to cover the objectives and variables of the study. It was designed after reading previous theoretical literature, studies, and articles, and after a full and comprehensive review of its contents in terms of the effects of website usability and accessibility for government website designs on the satisfaction of the end-user. It is represented by questionnaires, which is always linked with quantitative research. In different words, surveys are related to research that concentrates on numerals (how many? in what way often? in what way dissatisfied?). Therefore, surveys can be used in an assortment of survey situations [9]. On other hands, preferable practice, surveys should not be used to explore, debate, and investigate complicated issues in great deepness, or to discover problematic or like to be debatable issues. It should also not be used as an easy choice that requires little period or exertion, which is a shared fallacy [9].

\subsection{Statistical processing methods}

In order to achieve the objectives of the research, SPSS was used to analyze data and get results as follows: Cronbach Alpha was used to assess the reliability of data collection tools and their internal consistency; it can be defined as the internal consistency coefficient. According to Sekaran [19], the value of Cronbach's Alpha must be more than 0.70 to be acceptable. The testing of reliability for all variables in the current research was (0.86) and thus reflects the agreement of the terms related to people's opinions about the effects of website accessibility the effects of website usability and accessibility on the satisfaction of the end-user.

The following is an overview of some of the statistical methods and tests that were used, with an explanatory summary of each one from [20]:

- Frequency: Is the frequency of events occurring per unit of time. It is known as timefrequency and focuses on the variation between spatial frequency and angular frequency. It is mostly used to find the demographic characteristics of respondents.

- Descriptive: Is the analysis that measures mean and standard deviation values and is measured to give the degree of agreement of respondents on the questionnaire. 
- Cronbach Alpha: to evaluate the reliability of data collection tools and their internal consistency, it can be defined as the internal consistency coefficient.

- Regression test was adopted to examine the effects of website usability and accessibility for government website designs on the end-user satisfaction.

\subsection{Research population and sample}

The Research population consists of all users of the Jordanian government websites. Given the large size of the research community and the difficulty of restricting it, the study sample was randomly chosen from all spectrums of Jordanian society that uses Jordanian government websites, and across all spectrums. The survey was adopted electronically, to realize the aims of the research, which were specifically designed for the purposes of research, and formed. The research sample consisted of (427) respondents to the research. The questionnaires were retrieved and the questionnaires that were not answered seriously or in an objective manner were eliminated. The final research sample consisted of (387) respondents and responders. The research sample consisted of (387) distributed questionnaire. Table (1) shows the socio-demographic features of the participants. Table 1 demonstrates the socio-demographic characteristics of the participants. The male of participants make up 193 (49.9\%) of the total sampled individuals. while the female of participants makes up 194 (50.1\%) of the total sampled individuals. Separately, most of the participants age refers to $26-35$, which make up 171 (44.2\%) of the total sampled individuals.

Table 1. Socio-Demographic Characteristics of the Employee

\begin{tabular}{|l|c|}
\hline \multicolumn{1}{|c|}{ Variable } & N (\%) \\
\hline \multicolumn{2}{|c|}{ Gender } \\
\hline Male & $193(49.9 \%)$ \\
\hline \multicolumn{2}{|c|}{ Age } \\
\hline Lemale & $194(50.1 \%)$ \\
$26-35$ & $137(35.4 \%)$ \\
$36-45$ & $171(44.2 \%)$ \\
46 and above 25 years & $74(19.1 \%)$ \\
\hline
\end{tabular}

\section{$5 \quad$ Findings and Discussion}

This section of the research provides an analysis of the data collected through the questionnaire, which aims to discuss the effects of website usability and accessibility for government website designs on the end user's satisfaction with e-government websites, which have recently become a major place in Jordanian government systems. The data were analyzed using the SPSS system. 


\subsection{Descriptive statistics}

This section presented a descriptive analysis that showed the sample's views and agreement with the statements, which investigate participants' attitudes toward the effects of website usability and accessibility for government website designs on the satisfaction of the end-user about some e-government websites, which have recently become a major place in Jordanian government systems. The following section presented each statements with its accompanying mean and standard deviation, which will be used later on to explain the sample agreement of the effects of website usability and accessibility for government website designs on the end-user satisfaction about some of egovernment websites in Jordan, which have recently become a major place in Jordanian government systems with a sample the Jordanian society. The researcher used the general mean and percentages, and the estimation of respondents' responses to each of the statements. The researcher used the following criterion based on the mean value:

- 1 to 2.33 - Weak agreement

- 2.34 to 3.66 - Good agreement

- 3.67 to 5 - High agreement

Discuss answers of the research sample about the effects of website usability and accessibility on the satisfaction of the end-user with its statements.

First: Sample responses on the usability and accessibility statements

This part stands for usability and accessibility, which refer to the participants' level of arrangement with the below declarations about usability and accessibility. Table (2) shows the participants' agreement regarding usability and accessibility statements. In table (2), it seems that the general mean of all statement related to website usability is (3.30), which reflects a good agreement. Additionally, the standard deviation value is (1.30), which is standard and reflects coming together on the response of the sample. The highest mean is (3.51) for statement number 2 "I think it is easy to navigate between different site pages" which reflects good agreement and the lowest mean was (2.90) for statement number 4 "I think the fonts used on the site are easy to read", which reflects good agreement. In general, the sample attitude toward the statements was positive; thus, the participants were agreeing that website usability for government website designs in Jordan have good agreement, responses were positive towards that. Furthermore, in the table (2), it seems that the general mean of all statements related to website accessibility is (3.10), which reflects a good agreement. Moreover, the standard deviation value is (1.30), which is normal and reflects convergence on the response of the sample. The highest mean is (3.49) for statement number 8 "I think that the website design is available with attractive buttons to click on to facilitate accessibility", which reflects strong agreement. The lowest mean was (2.76) for statement's number 11 "I think that the website design is compatible with the mobile to achieve easy access to the site from anywhere, at any time", which reflects good agreement. In general, the sample attitude toward the questions was positive; thus, the participants were agreeing that website accessibility for government website designs in Jordan have good agreement, responses were positive towards that. 
Table 2. Usability and accessibility Analysis

\begin{tabular}{|c|c|c|c|}
\hline Statement & Mean & $\begin{array}{l}\text { Standard } \\
\text { deviation }\end{array}$ & Rank \\
\hline \multicolumn{4}{|l|}{ Website Usability } \\
\hline $\begin{array}{l}\text { 1. I didn't need to know much information about the e-gov- } \\
\text { ernment websites before I used it. }\end{array}$ & 3.32 & 1.433 & Good \\
\hline 2. I think it is easy to navigate between different site pages. & 3.51 & 1.313 & Good \\
\hline $\begin{array}{l}\text { 3. I expect most people will learn to use this site very eas- } \\
\text { ily. }\end{array}$ & 3.46 & 1.254 & Good \\
\hline 4. I think the fonts used on the site are easy to read. & 3.01 & 1.069 & Good \\
\hline 5. I think the icons used on the site are familiar to me. & 3.19 & 1.253 & Good \\
\hline $\begin{array}{l}\text { 6. I felt that the site design was not crowded and comforta- } \\
\text { ble to look at. }\end{array}$ & 3.15 & 1.370 & Good \\
\hline Total Mean and Standard Deviation & 3.30 & 1.30 & Good \\
\hline \multicolumn{4}{|l|}{ Website Accessibility } \\
\hline $\begin{array}{l}\text { 7. I think that the website design has an appearance Organ- } \\
\text { izer }\end{array}$ & 2.90 & 1.341 & Good \\
\hline $\begin{array}{l}\text { 8. I think that the website design is available with attractive } \\
\text { buttons to click on to facilitate accessibility }\end{array}$ & 3.49 & 1.269 & Good \\
\hline $\begin{array}{l}\text { 9. I think that the website design is in line with the visual be- } \\
\text { havior of the viewer to accessibility easily }\end{array}$ & 3.29 & 1.202 & Good \\
\hline $\begin{array}{l}\text { 10. I think that the information is displayed on the commer- } \\
\text { cial website according to its importance) from top to bottom, } \\
\text { and from left to right for easy access }\end{array}$ & 3.01 & 1.442 & Good \\
\hline $\begin{array}{l}\text { 11. I think that the website design is compatible with the mo- } \\
\text { bile to achieve easy access to the site from anywhere, at any } \\
\text { time. }\end{array}$ & 2.76 & 1.304 & Good \\
\hline Total Mean and Standard Deviation & 3.10 & 1.30 & Good \\
\hline
\end{tabular}

\section{Second: Sample responses on the End-user satisfaction statements}

This section represents end-user satisfaction for government website designs, which refers to the participants' level of agreement with the following statements about the end-user satisfaction for government website designs. Table (3) shows the participants' agreement regarding the end-user satisfaction statements. In the table (3), it seems that the general mean of all statement related to end-user satisfaction is (3.43), which reflects a good agreement. Moreover, the standard deviation value is (1.34), which is normal and reflects convergence on the response of the sample. The highest mean is ".for statement number 5 "Overall, I felt very confident when using the site (3.90) which reflects high agreement, and the lowest mean was (2.59) for statement number Overall, the government website is good business to do different services", which" 3 reflects good agreement. In general, the sample attitude toward the questions was positive; thus, the participants were agreeing that there is a good level of end-user satisfaction for government website designs in Jordan, and participants have a good satisfied to that. 
Table 3. End-user satisfaction Analysis

\begin{tabular}{|l|c|c|c|}
\hline \multicolumn{1}{|c|}{ Statement } & Mean & SD & Rank \\
\hline $\begin{array}{l}\text { 1. In general, I am very satisfied with the services offered by } \\
\text { government website. }\end{array}$ & 3.71 & 1.26 & High \\
$\begin{array}{l}\text { 2. Overall, I am very satisfied with relationship with govern- } \\
\text { ment website. }\end{array}$ & 3.78 & 1.11 & High \\
\hline $\begin{array}{l}\text { l. Overall, the government website is good business to do dif- } \\
\text { ferent services. }\end{array}$ & 2.59 & 1.8 & Good \\
\hline $\begin{array}{l}\text { 4. Overall, the service of the government website comes up to } \\
\text { my expectations. }\end{array}$ & 3.18 & 1.41 & good \\
\hline $\begin{array}{l}\text { 5. Overall, I felt very confident when using the site. } \\
\text { Total Mean and Standard Deviation }\end{array}$ & 3.90 & 1.12 & High \\
\hline
\end{tabular}

\subsection{Findings of the research questions}

Q1: Are there effects of website usability for government website designs on end-user satisfaction?

To answer the first question the simple regression test was used to test the effect of the independent variable (website usability) on the dependent variable (end-user satisfaction). Table (4) shows the results of the correlation between the independent variable (website usability) on the dependent variable (end-user satisfaction).

The R-value (.685a) refers to the correlation between the independent variable (website usability) on the dependent variable (end-user satisfaction). R square for enduser satisfaction indicates that $47 \%$ change or variance in the end- user satisfaction can be expressed by the website usability, and the other remaining percentage (53\%) is expressed by other factors. The value of sigma (0.000) is less than the significant level $(\alpha=0.05)$, which indicates that there is a significant effect between website usability and end-user satisfaction on e-government websites in Jordan. According to Beta values (.685), the type of this effect is positive which means that any improvement and increased on website usability will increase the satisfaction of the end-user.

Table 4. Correlation and Variance between website usability and quality of end-user satisfaction

\begin{tabular}{|l|c|c|c|c|c|c|c|}
\hline \multicolumn{1}{|c|}{ Variables } & B value & R & R Square & $\begin{array}{c}\text { Adjusted R } \\
\text { Square }\end{array}$ & $\begin{array}{c}\text { Std. Error of } \\
\text { the Estimate }\end{array}$ & Sigma & Beta \\
\hline Constants & .884 & \multirow{2}{*}{$.685 \mathrm{a}$} & .470 & .468 & .50785 & .000 & .685 \\
\hline Website usability & .663 & & & .600 & & \\
\hline
\end{tabular}

According to the above explanation, the result shows that there is a positive effect of website usability on the satisfaction of the end-user on e-government website designs in Jordan.

Q2: Are there effects of website accessibility for government website designs on end-user satisfaction?

To answer the second question the simple regression test was used to test the effect of the independent variable (website accessibility) on the dependent variable (end-user 
satisfaction). Table (5) shows the obtained results of the correlation between the independent variable (website accessibility) on the dependent variable (end-user satisfaction). The R-value (.617824a ) refers to the correlation between the independent variable (website accessibility) on the dependent variable (end-user satisfaction). R square for end-user satisfaction indicates that $38.1 \%$ change or variance in the end-user satisfaction can be expressed by website accessibility, and the other remaining percentage $(61.9 \%)$ is expressed by other factors. The value of sigma (0.00) is less than the significant level $(\alpha=0.05)$, which indicates that there is a significant effect between website accessibility and end-user satisfaction on e-government websites in Jordan, and according to Beta values (.617), the type of this effect is positive which means that any improvement and increased on website accessibility will increase end-user satisfaction.

Table 5. Correlation and Variance between website accessibility and end-user satisfaction

\begin{tabular}{|c|c|c|c|c|c|c|c|}
\hline Variables & B value & $\mathbf{R}$ & R Square & $\begin{array}{c}\text { Adjusted R } \\
\text { Square }\end{array}$ & $\begin{array}{l}\text { Std. Error of } \\
\text { the Estimate }\end{array}$ & Sigma & Beta \\
\hline Constants & .900 & & & & & & \\
\hline accessibility & .676 & $.617 \mathrm{a}$ & .381 & .379 & .54872 & .000 & .617 \\
\hline
\end{tabular}

According to the above explanation, the result shows that there is a positive effect of website accessibility on the satisfaction of the end-user on e-government website designs in Jordan.

\section{Conclusion}

Almost all the participants had a positive agreeing that website usability for government website designs in Jordan. Also, the participants were agreeing that website accessibility for government website designs in Jordan have a good agreement, responses were positive towards that. Many of the participants also said that there is a positive effect of website usability on the satisfaction of the end-user on e-government website designs in Jordan. Many participants found that there is a positive effect of website accessibility on the satisfaction of the end-user on e-government website designs in Jordan. Thus, the research recommended that:

- The user interfaces in the Jordanian e-government website must further be developed to attract more users and maintaining user satisfaction.

- The Accessibility website at the e-government website in Jordan must further be developed to attract more users and maintaining user satisfaction.

- Jordan e-Government systems must be maintaining a high degree of integration and flexibility to attract more users. 


\section{$7 \quad$ References}

[1] Almarabeh, T. and AbuAli, A. (2010). A general framework for e-government: definition maturity challenges, opportunities, and success. European Journal of Scientific Research, 39(1), 29-42.

[2] Alwaer, H., \& Clements-Croome, D. J. (2010). Key performance indicators (KPIs) and priority setting in using the multi-attribute approach for assessing sustainable intelligent buildings. Building and environment, 45(4), 799-807. https://doi.org/10.1016/j.buildenv. 2009.08.019

[3] Apel, S., Batory, D., Kästner, C., \& Saake, G. (2016). Feature-oriented software product lines. Springer-Verlag Berlin An. https://doi.org/10.1007/978-3-642-37521-7_2

[4] Al-Fawwaz, B. M. (2011). Evaluation of e-Government websites usability in Jordan (Doctoral dissertation. Brunel University School of Engineering and Design PhD Theses).

[5] Brajnik, G. (2004). Using automatic tools in accessibility and usability assurance processes. In ERCIM Workshop on User Interfaces for All (pp. 219-234). Springer, Berlin, Heidelberg. https://doi.org/10.1007/978-3-540-30111-0 18

[6] Choudrie, J., Wisal, J. and Ghinea, G. (2009). Evaluating the usability of developing countries'-government sites: a user perspective. Electronic Government, an International Journal, 6(3), 265-281. https://doi.org/10.1504/eg.2009.024944

[7] Costagliola, G., Ferrucci, F., Gravino, C., Tortora, G., \& Vitiello, G. (2004). The Impact of Accessibility and Usability on the Development of Web Applications. In ICWE Workshops (pp. 296-306).

[8] Dawson, M., DeWalt, B., \& Cleveland, S. (2016). The case for UBUNTU Linux operating system performance and usability for use in higher education in a virtualized environment.

[9] Greasley P. (2008). Quantitative Data Analysis Using SPSS an Introduction for Health and Social Science, 2nd edition. Maidenhead, UK: Open University Press.

[10] Grover, V., Prakash, A., \& Sivaram, S. (2019). U.S. Patent No. 10,489,005. Washington, DC: U.S. Patent and Trademark Office.

[11] Huang, Z. (2010) Usability and credibility evaluation of electronic governments: users' perspective (Doctoral dissertation, Brunel University, School of Information Systems, Computing and Mathematics).

[12] Huber, W., \& Vitouch, P. (2008). Usability and accessibility on the internet: Effects of accessible web design on usability. In International Conference on Computers for Handicapped Persons (pp. 482-489). Springer, Berlin, Heidelberg. https://doi.org/10.1007/978-3540-70540-6 69

[13] Kolekar, S. V., Pai, R. M., \& MM, M. P. (2019). Rule based adaptive user interface for adaptive E-learning system. Education and Information Technologies, 24(1), 613-641. https://doi.org/10.1007/s10639-018-9788-1

[14] Levin, S. P., \& Levin, M. (2019). Managing Ideas, People, and Projects: Organizational Tools and Strategies for Researchers. iScience. https://doi.org/10.1016/j.isci.2019.09.017

[15] McNamara, L. A., Berg, L., Butler, K., \& Klein, L. (2017, May). Does this interface make my sensor look bad? Basic principles for designing usable, useful interfaces for sensor technology operators. In Ground/Air Multisensor Interoperability, Integration, and Networking for Persistent ISR VIII (Vol. 10190, p. 101900O). International Society for Optics and Photonics. https://doi.org/10.1117/12.2266890

[16] Paris, M. (2006) Website accessibility: a survey of local e-government websites and legislation in Northern Ireland. Universal access in the information society, 4(4), 292-299. https://doi.org/10.1007/s10209-003-0081-7 
[17] Patalano, S., Lanzotti, A., Del Giudice, D. M., Vitolo, F., \& Gerbino, S. (2017). On the usability assessment of the graphical user interface related to a digital pattern software tool. International Journal on Interactive Design and Manufacturing (IJIDeM), 11(3), 457-469. https://doi.org/10.1007/s12008-015-0287-y

[18] Rodríguez, F. D., \& Acuna, S. T. (2013). Reuse of a usability functionality implementation in web applications. Procedia Technology. https://doi.org/10.1016/j.protcy.2013.12.026

[19] Sekaran, U. (2003). Research method for business: A skill Approach. New Jersey: John Willey and Sons, Inc.

[20] Sekaran, U., \& Bougie, R. (2013). Research methods for business - A skill building approach, 6th edition. West Sussex, United Kingdom: John Wiley \& Sons.

[21] Hussain, A., \& Omar, A. M. (2020). Usability Evaluation Model for Mobile Visually Impaired Applications. International Journal of Interactive Mobile Technologies (iJIM), 14(05), 95-107. https://doi.org/10.3991/ijim.v14i05.13349

[22] Hussain, A., Mkpojiogu, E. O., Ishak, N., Mokhtar, N., \& Ani, Z. C. (2019). An Interview Report on Users' Perception about the Usability Performance of a Mobile E-Government Application. International Journal of Interactive Mobile Technologies (iJIM), 13(10), 169178. https://doi.org/10.3991/ijim.v13i10.11286

[23] Kharma, Q., Turab, N. M., Shambour, Q., \& Hassan, M. (2020). Secure Cloud-Mediator Architecture for Mobile-Government using RBAC and DUKPT. International Journal of Interactive Mobile Tech-nologies (iJIM), 14(04), 44-60. https://doi.org/10.3991/ijim.v14 $\underline{\mathrm{i} 04.11075}$

\section{Author}

Mohammad H. Alshira'H is an Assistant Professor at the Information Systems Department at Al al-Bayt University. He obtained his $\mathrm{PhD}$ in Software Engineering at the Department of Computer Science of the University of Leicester in the United Kingdom in 2016.

Article submitted 2020-04-06. Resubmitted 2020-05-17. Final acceptance 2020-05-18. Final version published as submitted by the authors. 